\title{
Intervention and focus in Asante Twi
}

\author{
Gregory Kobele \\ University of California, Los Angeles
}

Harold Torrence

University of Kansas

This paper concerns the distribution of wh-words in Asante Twi, which has both a focus fronting strategy and an in-situ strategy. We show that the focusing and the in-situ constructions are not simply equally available options. On the contrary, there are several cases where the focusing strategy must be used and the in-situ strategy is ungrammatical. We show that the cases in Asante Twi are "intervention effects", which are attested in other languages, like German, Korean, and French. We identify a core set of intervening elements that all of these languages have and discuss their properties.

\section{Introduction}

This paper presents an initial distributional analysis of focused and in-situ whitems in Asante Twi, a Kwa language of Ghana. ${ }^{1}$ The basic paradigm given in (1) shows that there are two ways of forming simple wh-questions:
a. Kofi bos ama $^{2}$
kofi hit.past ama
'kofi hit ama'

1 We heap great thanks on our consultant Selassie Ahorlu for his patience and insight in answering our many questions. Thanks also to David Adu Amankwah for comparative judgements on some of the data we present. Unless otherwise specified, all Asante Twi data that we present comes from elicitations with our consultant.

2 Although Asante twi is a tone language, tone is not indicated in Asante Twi orthography (nor for any of the Akan dialects). In trying to keep as close as possible to that orthography, we have not marked tones, except in the examples in (2) to show that tone plays a grammatical as well as lexical function. Tone does not seem to be specifically relevant to the phenomena we discuss here. 

b. kofi bos hena
in-situ wh
kofi hit.past who
'who did kofi hit?'
c. hena na kofi bos (no) focused wh who na kofi hit.past $3 \mathrm{sg}$
'who is it that kofi hit?'

Although Asante Twi has an in-situ construction (1b) and a focus construction (1c), they are not equally available. Specifically, we look at a range of cases in which the wh-in-situ is unavailable and the wh-phrase must be focused, as in 1c. There are two main goals in this paper. The first goal is a Twi-specific one of gaining an understanding of the factors that play a role in determining whether a wh-word must be focused. The second goal is to place Asante Twi in a cross-linguistic context and see if similar phenomena are attested in other languages.

Section 2 presents background information on Asante Twi necessary for the following sections. Section 3 introduces the basics of wh-constructions in the language and looks at the properties of the focused and in-situ constructions. Section 4 presents cases in which a wh-word must be focused. Section 5 introduces phenomena similar to what is observed in Asante Twi, but in genetically unrelated languages. In Section 6, we highlight some of the differences between the Asante Twi data and how this fits in with the typology. The final section summarizes the results.

\section{Background}

Asante Twi is SVO with generally head-initial characteristics (e.g. postnominal relative clauses; $\mathrm{N}$ precedes determiners, adjectives, and numerals; adverbial modifiers follow adjectives, etc).

Before looking at focus clauses, it will be useful to consider the derivation of simple matrix clauses:
a. kòfí böj àmà
$V_{\mathrm{V}}=\mathrm{bj}$
kofi hit.past ama
'kofi hit ama'

b. kòfí hùù àmà

$V_{\mathrm{V}}=$ hù

kofi see.past ama

'kofi saw ama' 


\section{c. kòfí ámbó àmà \\ kofi past.neg.hit ama \\ 'kofi did not hit ama'}

There is no single segmental spellout of the past tense morpheme. Instead, past tense consists of a short vowel template $(-V)$ whose segmental content is supplied by the vowel in the verb root. This can be seen by comparing the past tense forms of verbs whose root vowels differ. In the two past affirmative clauses, 3a-b, past tense is realized as lengthening of the final vowel of the verb bj "hit" and hù "see". ${ }^{3}$ We therefore take past tense to be suffix on the verb. In the negative, $3 \mathrm{c}$, the verb carries an $a$-prefix, whose meaning is unclear, and the negative prefix $n$ - (which assimilates in place to the following consonant). ${ }^{4}$ Note also that the tone of the verb differs in the affirmative and negative. That past tense occurs as a suffix on $\mathrm{V}$ follows from $\mathrm{V}$-to-T raising:

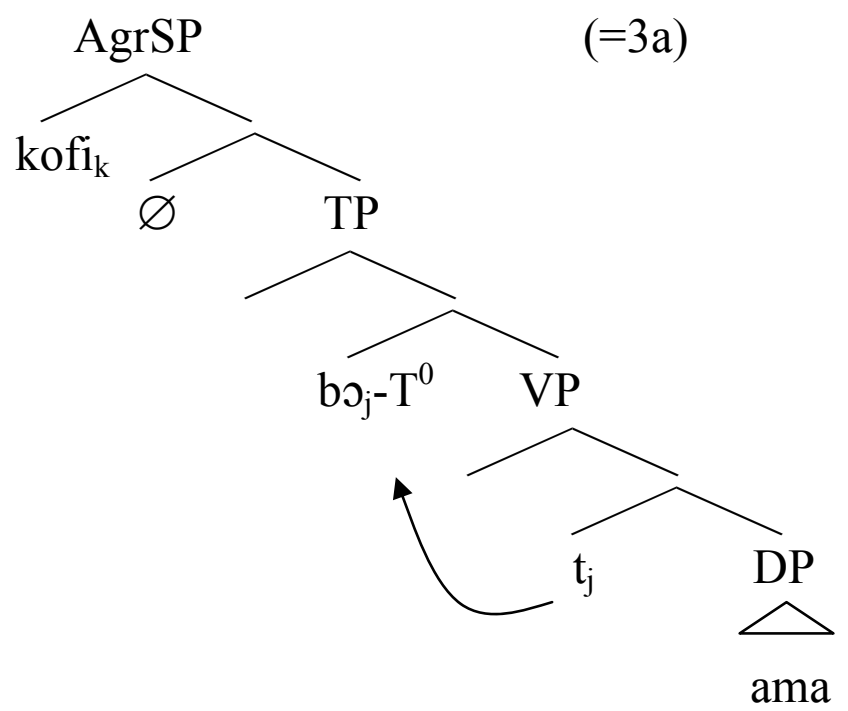

The spellout of $b \dot{j}-T^{0}$ is $b \mathfrak{j o j}^{5}$.

3 Dolphyne 1988 provides a detailed description of the segmental phonology and tonology of Asante Twi verb forms.

4 We call $a$ - and $n$ - "prefixes" on the verb because the $a-n-V$ string is a domain of vowel harmony.

5 We have written the derivation as head movement of $\mathrm{V}$ to $\mathrm{T}$ for the sake of concreteness, although it could be XP movement. It is not relevant for our purposes here. 
Consider next the negative in $(3 \mathrm{c})$ :

(4)

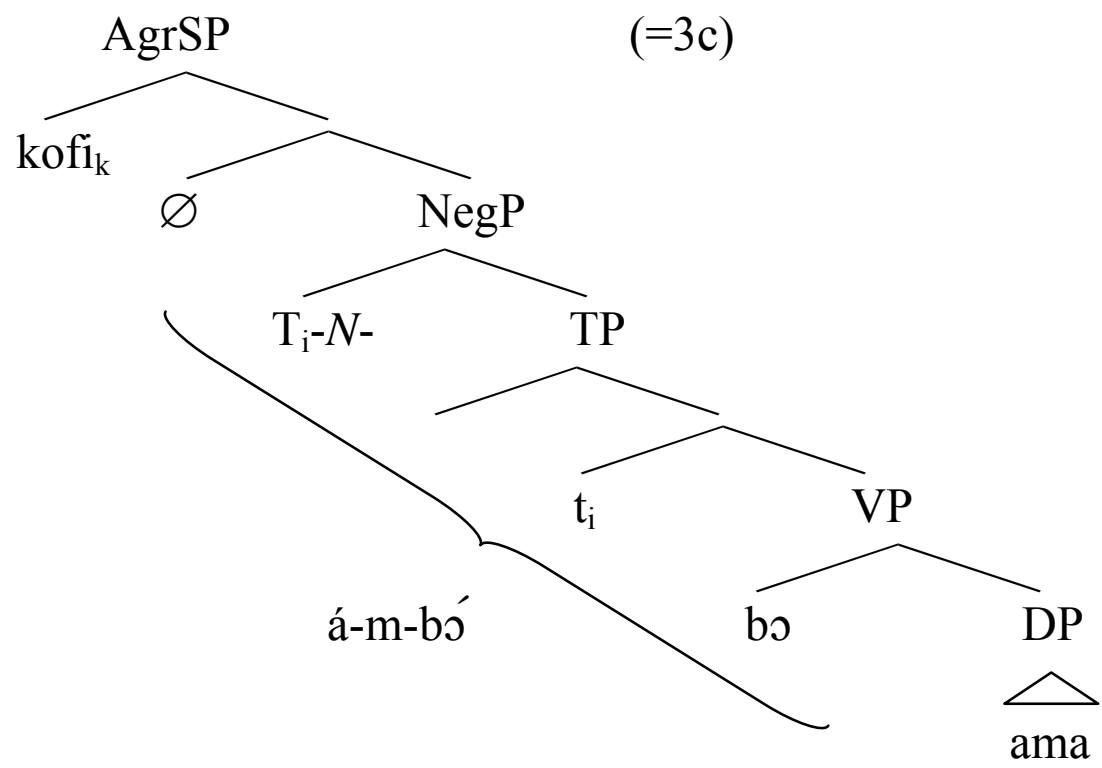

The spellout of $\mathrm{T}_{\text {past }}-\mathrm{NegP}$ and $\mathrm{V}$ is á-m-bo'. Negation is realized as a homorganic nasal, written as $N$ in the tree in (4). Thus, in (2c)/(4), negation is pronounced as [m] when it precedes the initial [b-] of bo "hit". It is important to note that the direct object, ama, in (2c) is in the c-command domain of the negative $n-$. That this is so can be seen from the fact that sensitive negative polarity items are licensed in the direct object position (Kobele and Torrence 2004):
kofi a-*(m)-bo hwee
kofi $a$-neg-hit anything
'kofi did not hit anything'

Focus is morphosyntactically marked by the presence of $n a$ in the left periphery of CP. As (6) shows, the na focus marker immediately follows the XP in focus:
a. $(\varepsilon-y \varepsilon)$ kofi
na $*(0)-$ bos
ama (no)
subject focus it-is kofi na 3sg-hit.past ama det 'it's kofi who hit ama'
b. ( $\varepsilon-y \varepsilon)$ ama na kofi bos (no) (no) it-is ama na kofi hit.past 3sg det 'it's ama who kofi hit'
direct object focus 
c. $(\varepsilon-y \varepsilon)$ bo na kofi bos ama it-is hit na kofi hit.past ama 'hit is what kofi did to ama'

d. $(\varepsilon-y \varepsilon)$ ennra na kofi boo ama adverb in focus ${ }^{6}$ it-is yesterday na kofi hit.past ama 'it's yesterday that kofi hit ama'

e. $\varepsilon$-ye me

it-is me

'it's me'

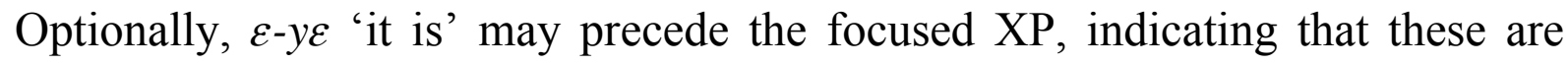
cleft constructions. This conclusion is reinforced by the appearance of $\varepsilon-y \varepsilon$ in presentational copular clauses like (6e). Note that Asante Twi allows for predicate clefting (6c). An optional right peripheral determiner-like element, no, may also occur in clefts. ${ }^{7}$

Templatically, focus clauses can be represented as:

$$
(\varepsilon-y \varepsilon)[\text { Focused XP ] na }[\text { AgrsP S V O ] (no) }
$$

\section{Wh-questions in Asante Twi}

Asante Twi allows both in-situ and focus clefted wh-words, as shown earlier: ${ }^{8}$
a. kofi bos
hena
in-situ wh
kofi hit.past who
'who did kofi hit?'

\footnotetext{
6 There are restrictions on which adverbs can be focused in Asante Twi. See also, (Saah 2004).

7 The presence of the right peripheral no seems to add some type of "emphasis". This element is homophonous with the definite determiner and exhibits cooccurrence restrictions with various tenses/aspects. Thus, it looks somewhat similar to the "clausal" or "event" determiners found in other Kwa languages like Fongbe and in Haitian Creole (Lefebvre 1998). In Asante Twi, this element only seems to occur when a thuman DP undergoes A'-extraction.

8 Saah (1988) notes that both in-situ and focused wh-words are possible. His data is from "Akan", but we do not know which dialect (Asante, Fante, Akuapem, etc.).
} 
b. hena na kofi bos (no) focused wh
who na kofi hit.past 3sg
'who is it that kofi hit?'

While a direct object wh can remain in situ (8a), Saah 1988 observes that a wh-subject cannot be in-situ:
a. *hena bos ama who hit.past ama
'who hit ama?'
*subject wh in-situ
b. hena na o-bos ama who na 3sg-hit.past ama 'who is it that hit ama?'

The descriptive generalization is that a subject wh-word cannot be in situ, but a direct object wh may be in-situ or focused into the left periphery. Because it is non-subjects that make use of both the focus and in-situ strategies, from this point onward, we concentrate on non-subjects.

\section{$4 \quad$ Obligatory focusing of wh-phrases}

We will be concerned below with cases in which modifications elsewhere in the sentence render an in-situ wh-phrase ungrammatical. In Section 3 it was shown that, in the simple case, Asante Twi has two strategies for constructing wh-questions. However, as we show, the focusing and in-situ strategies are not created equally. This is because there are several contexts in which a nonsubject wh-word must be focused. The first of these contexts involves negation:

$$
\begin{aligned}
& \text { a. kofi bos hena } \\
& \text { kofi hit.past who } \\
& \text { 'who did kofi hit?' } \\
& \begin{array}{l}
\text { b. *kofi a-m-bo hena } \quad \text { *neg...wh } \\
\text { kofi past-neg-hit who } \\
\text { 'who didn't kofi hit?' }
\end{array} \\
& \begin{array}{llllll}
\text { c. hena na kofi } & \text { a-m-bo } & \text { (no) } & \checkmark \text { wh...neg } \\
\text { who na kofi } & \text { past-neg-hit } & 3 \text { sg } &
\end{array} \\
& \text { 'who is it that kofi didn't hit?' } \\
& \text { (i.e. 'which person is such that kofi did not hit that person?') }
\end{aligned}
$$


(10a) presents the base case with the wh-word in situ. Comparing (10b) to (10c), it can be seen that when negation is present on the verb, a direct object wh-word must be focused.

Structurally, the ungrammatical $(10 \mathrm{~b})$ is represented as:

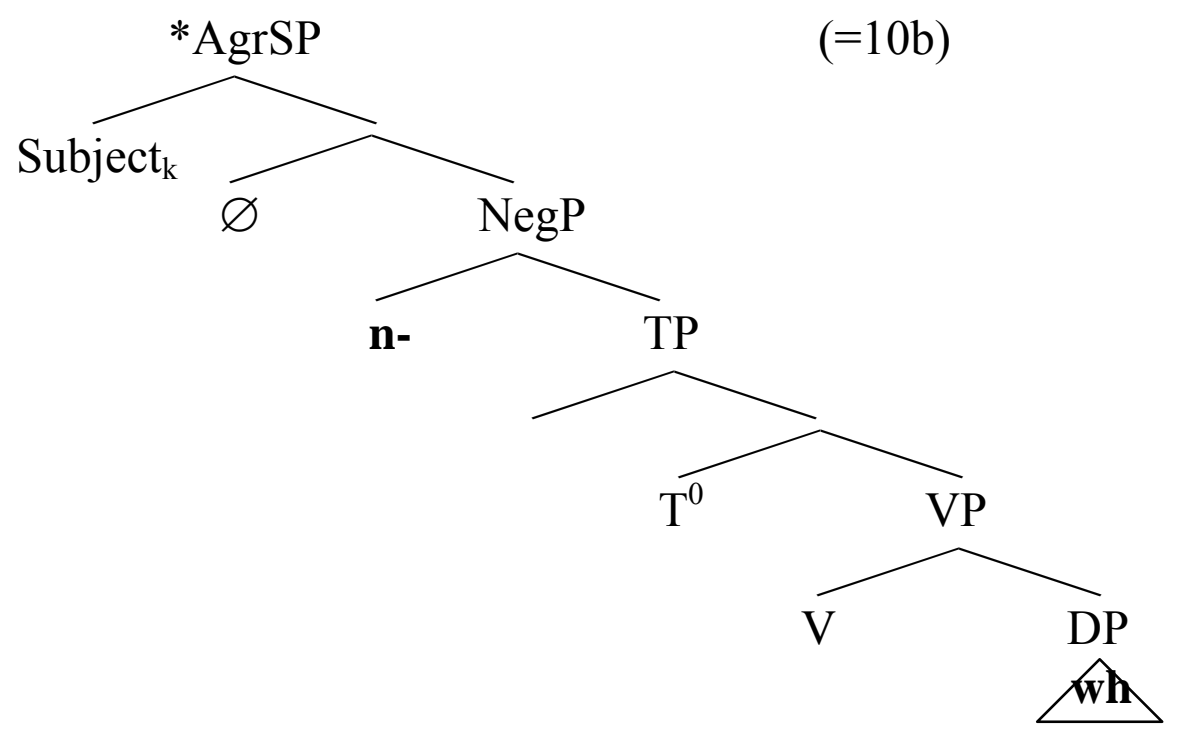

The same pattern holds with "only" phrases":
a. *kofi nko-ara bos hena kofi only-emph hit.past who 'who did only kofi hit?'

b. hena na kofi nko-ara bos (no) who na kofi only-emph hit.past 3 sg 'who is it that only kofi hit?'

As with negation, when the wh-word follows the focus-sensitive particle nkoara "only" (12a), the result is ungrammatical. In the grammatical construction in

9 Saah (1994) discusses cases such as the following, where modification of the wh-phrase itself (for example, with nko ara 'only') leads to obligatory focusing of that phrase:
(i) *wo-huu hena nko-ara 2sg-see.past who only-emph
(ii) hena nko-ara na wo-huu no who only-emph na 2sg-see.past 3sg 'only who did you see' (who is such that you saw only him) 
(12b), the wh-word has been focused into the left periphery so that it precedes the focus-sensitive particle.

Consider next another focus-sensitive particle, mpo "even":
a. *kofi mpo bos hena kofi even hit.past who 'who did even kofi hit?'
b. hena na kofi mpo bos (no) who na kofi even hit.past 3 sg 'who is it that even kofi hit?'

Comparing the data in (12) and (13), it can be seen that the focus-sensitive particles pattern alike with respect to their ordering in wh-clauses. Simply put, the focus-sensitive particles cannot c-command the wh-word, but they may c-command the trace of the wh:

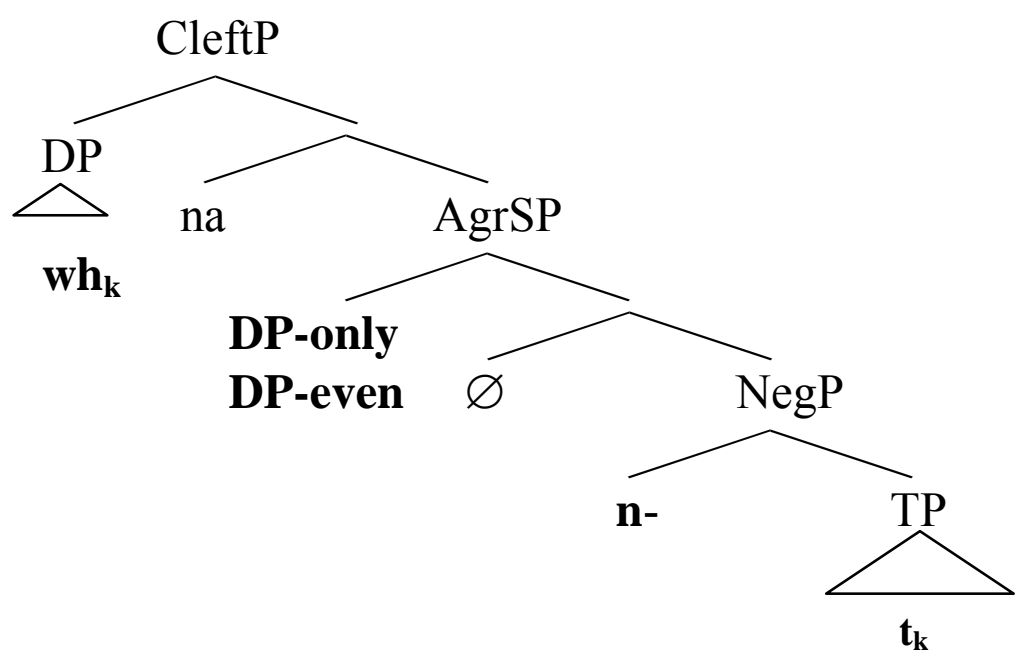

In addition, certain kinds of embedded clauses do not allow for an in-situ whword:
a. *wo dwene [CP (se) kofi bos hena ] you think
C kofi hit.past who
'who do you think that kofi hit?'
b. *wo dwene [CP (se) hena na kofi bos (no) ] you think $\mathrm{C}$ who na kofi hit.past $3 \mathrm{sg}$ 'who do you think that it is that kofi hit?'



c. hena na wo dwene [CP $\boldsymbol{S \boldsymbol { \varepsilon }}$ kofi bos (no) ] who na you think $\mathrm{C}$ kofi hit.past 3sg 'who is it that you think that kofi hit?'

These can be represented as:

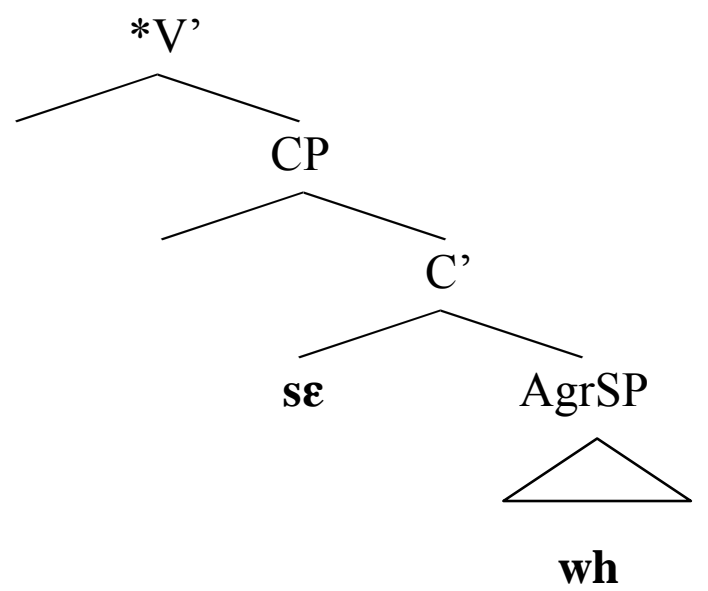

Putting the data in this section together, we see that there are four conditions under which a wh-phrase must be focused. In the first condition, the wh-phrase must be focused if it occurs to the right of negation $n-$. In the second and third conditions, the wh-phrase must be focused if its in-situ position occurs to the right of focus sensitive particles like the Asante Twi equivalents of even or only. Finally, it was shown that a wh-phrase cannot occur in-situ in an embedded clause. In all of the ungrammatical cases, some element intervenes between the in-situ wh-position and the clefted position where a focused wh appears:

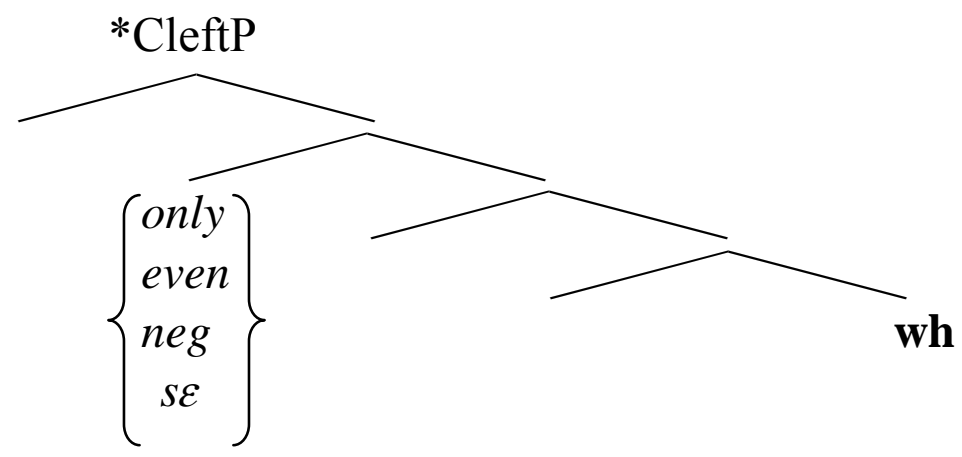

In all of the grammatical cases, the intervening elements c-command only the trace of the wh-word on the surface. ${ }^{10}$

10 Saah (1989) indicates that reflexives, subject to Principle A of the Binding Theory, can be clefted. This suggests that clefts in Asante Twi are indeed derived by movement of the clefted constituent. This fits in with the typological conclusions in (Aboh 2004), namely that focus constructions in Kwa involve either head movement or XP movement. 
The descriptive generalization concerning the grammatical cases can be roughly represented as:

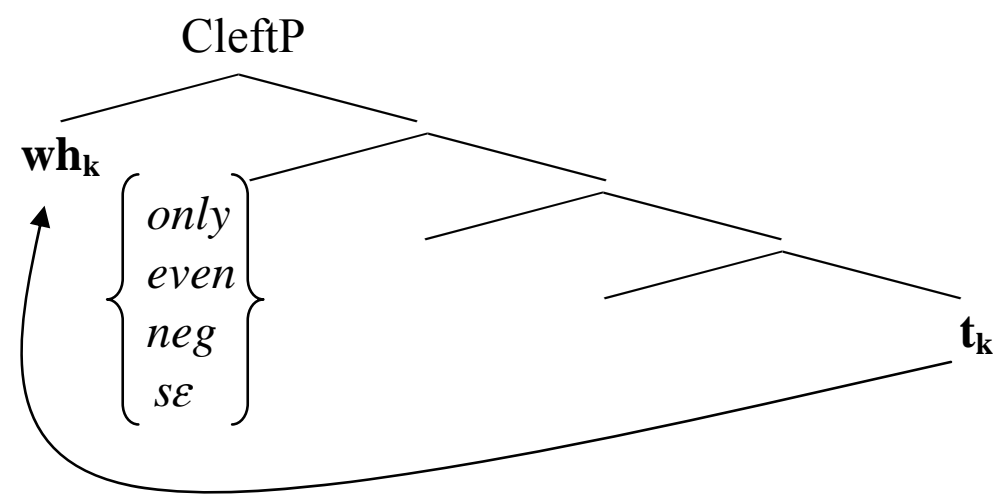

The patterns given above for Twi are strikingly similar to those found in other languages, where so called "intervention effects" have been studied.

\section{Intervention effects cross-linguistically}

Having established the basic wh-in-situ versus focused wh- paradigm in Asante Twi, we now turn to other languages, where similar phenomena have been observed. In Beck 1996, it was observed that in German, a scrambling language, the ordering of wh-words and negation is not free: ${ }^{11}$

German

a. ??wen hat niemand wo gesehen *neg...wh who.acc has nobody.nom where seen 'who did nobody see where?'

b. wen hat wo niemand gesehen $\checkmark$ wh...neg who.acc has where nobody.nom seen 'who did nobody see where?'

As the examples in (19) show, when a wh-word follows a negative quantifier (19a), near ungrammaticality results. However, when the wh-word precedes the negative quantifier, the result is fine (19b). In other words, a wh-word cannot surface in the c-command domain of negation (in the German-specific case a

11 Throughout, the sources for the data are:

German: (Beck 1996), (Beck and Kim 1996), (Beck and Kim 1997), (Chen and Rooryck 2000), (Sauerland and Heck 2003).

French: (Matthieu 1999), (Zubizarreta n.d.)

Korean: (Beck and Kim 1996), (Beck and Kim 1997), (Kim 2002), (Kim 2003) 
negative quantifier). Making the comparison to Asante Twi explicit, in German a wh-word cannot occur in-situ when negation c-commands it (19a). When the wh-word is fronted so that the negation c-commands only the wh-trace, the clause is grammatical (19b). When a negative element occurs between the in-situ position of a wh-word and the focused (fronted) position of a wh-word, ungrammaticality results. Thus, negation can be thought of as an intervening element occurring in the pathway of (LF) wh-movement. More generally, an "intervention effect" arises when the presence of a word or phrase (the intervener) in a sentence rules out otherwise available surface positions of another word or phrase. In the cases studied here, the intervener is usually a scope-taking element (negation, a quantifier, etc.), and its presence in a sentence rules out wh-words appearing within its c-command domain on the surface. Strikingly, similar effects have been observed with negation for other languages aside from Asante Twi and German, witness Korean and French:

Korean (Beck and Kim 1996, 1997)
a. *?amuto muôs-ûl sa-chi anh-ass-ni *?neg...wh anyone what-acc buy-chi not.do-past-Q 'what did no one buy?'
b. muôs-ûl amuto sa-chi anh-ass-ni what-acc anyone buy-chi not.do-past-Q 'what did no one buy?' $\checkmark$ wh...neg

French (Bošković 1998, Matthieu 1999, Zubizarreta n.d.)
a. jean a mangé quoi jean has eaten what 'what did jean eat?' what is-it that jean has eaten 'what is it that jean ate?'
b. qu'est-ce que jean a mangé
c. *jean n'a pas mangé quoi jean neg-has neg eaten what 'what did jean not eat?'


d. qu'est-ce que jean n'a pas mangé $\quad \checkmark$ wh...neg what is-it that jean neg-has neg eaten 'what did jean not eat?'

The data in (20a-b) very closely match that of (10a-b) (Asante Twi) and (21c-d) (German). The pattern similarity between the Asante Twi data and that of other languages is not limited to negation, however. German, Korean, and French pattern like Asante Twi with respect to the ordering relation between wh-words and "only" phrases:

German

a. ??wen hat nur karl wo getroffen ??only...wh who.acc has only karl where met 'who did only karl meet where?'

b. wen hat wo nur karl getroffen $\checkmark$ wh...only who.acc has where only karl met 'who did only karl meet where?'

Korean
a. *? minsu-man nuku-lûl manna-ss-ni *only...wh minsu-only who-acc meet-past-Q 'who did only minsu meet?'
b. nuku-lûl minsu-man manna-ss-ni $\checkmark$ wh...only who-acc minsu-only meet-past-Q 'who did only minsu meet?'

French
a. *seulement jean arrive à faire quoi *only...wh only jean arrives to do what 'what does only jean manage to do?'
b. qu'est-ce que seulement jean arrive à fair $\checkmark$ wh...only what is-it that only jean arrives to do 'what does only jean manage to do?'


Just as in Asante Twi, wh-phrases cannot occur to the right of a focus-sensitive particle like only in (22a), (23a), and (24a) (See Appendix 1 for other focus-sensitive particles in French, German, and Korean that pattern like Asante Twi.)

To summarize, in this section we have shown that negation and focus sensitive particles have similar effects on the availability of wh in-situ crosslinguistically. That is, we first established a set of items in Asante Twi that cannot intervene between the surface position of a wh-word and its LF scope position. It turns out that this same set of items triggers intervention effects in genetically unrelated languages like German and Korean.

\section{Asante Twi in the cross-linguistic context}

While there is a core set of cross-linguistic interveners (negation and focus sensitive particles), Asante Twi displays several differences from other languages in which intervention effects have been studied. In this section we introduce some of these and discuss the implications for the understanding of intervention effects in general. It should be noted at the outset that Asante Twi wh-words are not used as indefinites. This is unlike the distribution of wh-words in languages like Korean, German, Chinese, and French. In addition, like most Kwa languages, the word order is relatively fixed. In other words, Asante Twi does not display scrambling phenomena, unlike German and Korean. The fact that Asante Twi differs in these ways from other languages with intervention effects suggests that the scrambling property, for instance, does not play a direct role in the presence of intervention effects.

When the paradigm of interveners is expanded, it turns out that not all of the interveners in other languages act as interveners in Asante Twi. This can be seen by comparing the behavior of universal quantifiers, in Asante Twi and German (see Appendix 2 for data from Korean and French):

Asante Twi
a. osuani bi-ara bos hena
student some-emph hit.past who
'who did every student hit?'
b. hena na osuani bi-ara bos (no)
who na student some-emph hit.past $3 \mathrm{sg}$
'who is it that every student hit?' 
German

a. ??wen hat fast jeder wo getroffen who.acc has almost everyone where met 'who did almost everyone meet where?'

b. wen hat wo fast jeder getroffen who.acc has where almost everyone met 'who did almost everyone meet where?'

Looking at the Asante Twi and German in (25a) and (26a), it is seen that the universal quantifier does not act as an intervener in Asante Twi. However, a universal does act as an intervener in German (0b versus $0 \mathrm{~b}$ ). It is not clear what to make of this difference because it is not obvious whether the difference in grammaticality is due to a property of wh-words in the languages or a property of universal quantifiers in the languages (or both).

In comparing Asante Twi to German, another difference in intervention effects obtains concerning stranding. In German, if the restriction on a whphrase is stranded under a negative quantifier, the result is ungrammatical:

German

a. *wen hat keine studentin von den musikern getroffen who.acc has no student of the musicians met 'which of the musicians has no student met?'

b. wen von den musikern hat keine studentin getroffen who.acc of the musicians has no student met 'which of the musicians has no student met?'

c. wen hat johannes von den musikern getroffen who.acc has johannes of the musicians met 'which of the musicians has Johannes met?'

The relevant contrast is between (27a) (stranding under negation) and (27b) (pied piping of the restriction). (27c) shows that stranding of the restriction is otherwise possible. 
However, similar cases in Asante Twi do not show this effect:
a. den na kofi a-n-di
no nyinaa
$\checkmark$ stranding
what na kofi past-neg-eat $3 \mathrm{sg}$ all
'what all did kofi not eat?'
('what are all of the things that have the property that kofi did not eat them?')
b. den nyinaa na kofi a-n-di
$\checkmark$ pied piping
what all na kofi past-neg-eat
'what all did kofi not eat?'
('what are all of the things that have the property that kofi did not eat them?')

One potentially relevant difference between Asante Twi and German is that in Asante Twi, the stranded quantifier contains a resumptive-like element no " $3 \mathrm{sg}$ ", while the German does not. In addition, the universal quantifier in (28a) obligatorily takes wide scope with respect to negation, even though it follows it. Thus, (28a) does not mean, "what thing is such that you did not eat all of it?". In other words, the quantifier somehow is able to outscope negation, even when it occurs in object position. (Recall that sensitive negative polarity items are licensed in object position (5)). Thus, the grammaticality of (28a) may be related to the ability of the quantifier nyinaa to obligatorily take scope over negation.

The final difference to be discussed here involves the availability of in-situ wh-words in embedded clauses. Recall the data introduced earlier: ${ }^{12}$

$$
\begin{aligned}
& \text { a. *wo dwene [CP (se) kofi bos hena ] } \\
& \text { you think C kofi hit.past who } \\
& \text { 'who do you think that kofi hit?' }
\end{aligned}
$$

b. *wo dwene [CP (se) hena na kofi bos (no) ] (=(15b)) you think $\mathrm{C}$ who na kofi hit.past $3 \mathrm{sg}$ 'who do you think that it is that kofi hit?'

c. hena na wo dwene [CP $\mathbf{s} \boldsymbol{\varepsilon}$ kofi bos (no)] who na you think $\mathrm{C}$ kofi hit.past 3sg 'who is it that you think that kofi hit?' 
We take the data in (15) as showing that a wh-word cannot occur in an embedded clause. Note that the complementizer in (29) is $s \varepsilon$. Surprisingly, in some cases, where the complementizer is $m a$ (which introduces factive clauses), an embedded wh-phrase is fine:

$$
\begin{aligned}
& \text { a. ye-hyee kofi }\left[{ }_{\mathrm{CP}} \text { ma ne nuaa den }\right]^{13} \\
& \text { we-force.past kofi C 3sg cook.past what } \\
& \text { 'what did we force kofi to cook?' }
\end{aligned}
$$

b. den na ye-hyee kofi [CP ma ne nuaae ] what na we-force.past kofi $\mathrm{C} 3 \mathrm{sg}$ cook.past 'what is it that we forced kofi to cook?'

$$
\begin{aligned}
& \text { a. wu bisaa kofi [ }{ }_{\mathrm{CP}} \text { ma ne nuaa den ] } \\
& \text { you ask.past kofi C 3sg cook.past what } \\
& \text { 'what did you ask kofi to cook (that he did in fact cook)?' }
\end{aligned}
$$

(30a) and (31a) contrast with (29a-b) in that the wh-words in the embedded clause are fine as long as the complementizer is $m a$ and not $s \varepsilon$. Note that $m a$ introduces tensed embedded clauses, just like $s \varepsilon$. The fact that one complementizer acts as an intervener while another does not may fall out purely from the syntax of successive-cyclic wh-movement. In that case, the question is why a wh-word can not move through the specifier of $s \varepsilon$ at LF. A similar the pattern obtains in French:

French
a. *pierre pense [CP que jean a mangé quoi ] pierre think that jean has eaten what 'what does Pierre think that jean ate?'

b. qu'est-ce [CP que pierre pense que jean a mangé ] what is-it that pierre thinks that jean has eaten 'what is it that Pierre thinks that jean ate?'

13 The complementizer ma also occurs with genitive or nominative case subjects in the embedded clause in some not-well-understood instances. 
(32a-b) show that a wh-word cannot appear in-situ in an embedded clause introduced by que. Consider the pattern of wh in-situ in non-finite embedded clauses introduced by de or a null complementizer:

French
a. *jean a décidé $\left[\begin{array}{ll}\text { de } & \text { faire quoi }\end{array}\right]$
jean has decided $\mathrm{C}$ to.do what
$\mathrm{C}=d e$ 'what has jean decided to do?'
b. qu'est-ce que jean a décidé [CP de faire $t_{k}$ ] what is-it that jean has decided $\mathrm{C}$ to.do 'what is it that jean has decided to do?'
c. jean a pensé $[\mathrm{CP}$ faire quoi $]$ jean has thought to.do what 'what did jean think about doing?' $\mathrm{C}=d e$ $\mathrm{C}=\varnothing$

(33a-b) show that in French a wh-word is not licensed in an embedded clause introduced by the non-finite complementizer de. However, the null complementizer has no such effect. Thus, it is not merely the property of being in an embedded clause that is responsible for the intervention effect in Asante Twi or French. Like Asante Twi, the French pattern may have to do with the structural composition of the left periphery of the clause

Having discussed some of the variables that impinge on intervention effects cross-linguistically, we point out here that in Asante Twi, the ban on wh-words following negation, for example, is not absolute:

$$
\begin{aligned}
& \text { hena }_{1} \text { na o-a-m-bo hena } \\
& \text { who na 3sg-past-neg-hit who } \\
& \text { 'who is it that did not hit who?' }
\end{aligned}
$$

Surprisingly, in the multiple wh-question in (34), the direct object wh, hena ${ }_{2}$, appears in the c-command domain of negation, but the sentence is good. ${ }^{14}$ Beck 1996 attempts to reduce intervention effects to the question of why particular elements act as barriers to movement under the assumption that the wh-phrases move at LF, and that the ungrammaticality arises when this movement is

14 The fact that a negative polarity item would be licensed in the same position as hena indicates that it is in the scope of negation. 
blocked. The Asante Twi data suggests that it is not necessarily a property of the wh-words that is the source of the problem in the ungrammatical cases.

Interestingly, it appears that the presence of the +wh-(focused)subject is critical for the grammaticality of (34): ${ }^{15}$

$$
\begin{aligned}
& \text { *kofi na o-m-bo hena } \\
& \text { kofi na 3sg-neg-hit who } \\
& \text { 'it's kofi that did not hit who?' }
\end{aligned}
$$

The alleviating effect of the "extra" wh-word is strongly reminiscent of the effect that a third wh-word has on Superiority in English:
a. who bought what?
b. *what did who buy?
c. ?what did who buy where?

(36a-b) show a canonical Superiority paradigm. (36c) shows that the addition of another wh-phrase greatly improves the grammaticality. Again, in (34), the lower wh-word should still be blocked from raising at LF because of the presence of the intervening negation. It is not clear why the presence of a wh-word higher than negation should have this alleviating effect.

\section{$7 \quad$ Summary and conclusions}

Asante Twi has been described as a language with both movement and in-situ options for wh-questions. However, these strategies are not equally available. We have given a descriptive refinement of the conditions under which the in-situ strategy is permitted, and pointed to similar effects which obtain in a number of unrelated (genealogically as well as typologically) languages. We end with a preliminary summary table comparing the Asante Twi data to that from other languages. A more complete typology and understanding how cross-linguistic variation in intervention effects arise await future research. ${ }^{16}$

15 Multiple wh-constructions in Twi exhibit different behavior than their presumably related single wh counterparts with respect to the availability of in-situ constructions. Saah (1994) gives the following multiple wh pair below, in which (ii) contains an otherwise ungrammatical in-situ wh subject:

(i) hena na o-huu den

who na 3sg-see.past what

(ii) den na hena hui

what na who see.past

'who saw what'

16 Appendix 3 presents other interveners not discussed here. 
Table 1. A typology of interveners for wh-phrases

\begin{tabular}{|l|l|l|l|l|}
\hline & Asante Twi & Korean & French & German \\
\hline word order & SVO & SOV & SVO & SOV, V2 \\
\hline $\begin{array}{l}\text { wh = } \\
\text { indefinite }\end{array}$ & no & yes & yes & yes \\
\hline scrambling & no & yes & no & yes \\
\hline Interveners & & & & \\
\hline negation & yes & yes & yes & yes \\
\hline "only" & yes & yes & yes & yes \\
\hline "even" & yes & yes & yes & yes \\
\hline "every/all" & no & maybe & yes & yes \\
\hline "always" & no & no & yes & no data \\
\hline "often" & no & no & yes & no data \\
\hline
\end{tabular}




\section{Appendix $1 \quad$ Focus-sensitive particles}

German "exactly" Phrases ${ }^{17}$

a. *?fritz ratterte runter wer gestern genau wann angekommen ist fritz rattled off who yesterday exactly when arrived is 'fritz rattled off exactly when who arrived'

b. fritz ratterte runter wer gestern wann genau angekommen ist fritze rattled off who yesterday when exactly arrived is 'fritz rattled off exactly when who arrived'

Korean "too" Phrases

a. *?minsu-to nuku-lûl manna-ss-ni minsu-also who-acc meet-past-Q 'who did minsu too, meet?'

b. nuku-lûl minsu-to manna-ss-ni who-acc minsu-also meet-past-Q 'who did minsu too, meet?'

French “even” Phrases

a. *même jean arrive à faire quoi even jean arrives to do what 'what does even jean manage to do?'

b. qu'est-ce que même jean arrive à faire what is-it that even jean arrives to do 'what does even jean manage to do?'

17 The examples in (37)a-b are adapted from Sauerland and Heck (2003). 


\section{Appendix $2 \quad$ Universal quantifiers}

French

(40) a. tous les étudiants ont rencontré qui

all the students have met who

'who have all of the students met?'

(* wh $>\forall, \checkmark \forall>$ wh)

b. qui est-ce que tous les étudiants ont rencontré who is-it that all the students have met 'who is it that all of the students have met?' (wh $>\forall, \checkmark \forall>$ wh)

(41) a. pierre a acheté plusieurs livres pierre has bought several books

b. il a envoyé chacun de livres à qui he has sent each of books to who 'who did he send each of the books to?'

Korean

(42) a. ?(?) nukuna-ka ônû kyosu-lûl chonkyôngha-ni everyone-nom which professor-acc respect-Q 'which professor does everyone respect?'

b. ônû kyosu-lûl nukuna-ka chonkyôngha-ni which professor-acc everyone-nom respect-Q 'which professor does everyone respect?' 


\section{Appendix $3 \quad$ Other interveners}

Korean “most” Phrases

(43) taeupun-ûl hansaeng-tûl-i nuku-lûl hoichang-ûlo ch'uch'ônha-ôss-ni most-gen student-pl-nom who-acc president-as recommend-past-Q 'who did most students recommend as president?'

Korean "always" and "only" Phrases

(44) minsu-nûn hangsang/chachu nuku- lûl p'at'i-e telikoka-ss-ni minsu-TOP always/often who-acc party-to take-past-Q 'who did minsu always/often take to the party?'

French “often” Phrases

a. *il mange souvent quoi he eats often what 'what does he often eat?'

b. qu'est-ce que il mange souvent what is-it that he eats often 'what is it that he often eats?'

French "always" Phrases
a. *il visite toujours qui he visits always who 'who does he always visit?'

b. qui est-ce que il visite toujours who is-it that he visits always 'who does he always visit?' 


\section{$8 \quad$ References}

Aboh, E. (2004) Focus constructions across Kwa. Kinyira Njira!-Step Firmly on the Pathway. In: Githiora, Littlefield, and Manfredi (eds.) Trends in African Linguistics 6. Trenton, NJ: Africa World Press, 7-22

Beck, S. (1996) Quantified structures as barriers for LF movement. Natural Language Semantics, 4: 1-56.

Beck, S. \& S.-S. Kim (1996) On WH- and Operator Scope in Korean. Arbeitspapiere des SFB 340. Bericht Nr. 73, February.

Beck, S. \& S.-S. Kim (1997) On WH- and Operator Scope in Korean. Journal of East Asian Linguistics, 6: 339-384.

Cheng, L. \& J. Rooryck (2000) Licensing WH-in-Situ. Syntax, 3, 1: 1-19.

Dolphyne, F. (1988) The Akan (Twi-Fante) Language: Its Sound Systems and Tonal Structure. Accra: Ghana Universities Press.

Kim, S.-S. (2002) Intervention Effects are Focus Effects. Japanese/Korean Linguistics, 10. Stanford, California: Center for the Study of Languageand Information.

Kim, S.-Y. (2003) On Beck's Intervention Effects. Studies in Generative Grammar, 13, 4. Korea: Korean Generative Grammar Circle.

Kobele, G. \& H. Torrence (2004) The Syntax of Complement Clauses in Asante Twi. (MS., UCLA)

Lefebvre, C. (1998) Multifunctionality and Variation Among Grammars: The Case of the Determiner in Haitian and in Fongbe. Journal of Pidgin and CreoleLanguages, 13: 93150.

Matthieu, E. (1999) WH in situ and the intervention effect. University College London Working Papers in Linguistics, 11: 441-474.

Miyagawa, S. (2002) The Nature of Weak Islands. Handout.WHERE?

Saah, K. (1988) WH-questions in Akan. Journal of West African Languages, 18, 1: 17-28.

Saah, K. (1989) Reflexivization in Akan. Journal of West African Languages,19, 2: 15-28.

Saah, K. (1994) Studies in Akan Syntax, Acquisition, and Sentence Processing. PhD. Thesis, University of Ottawa.

Saah, K. (2004) A Survey of Akan Adverbs and Adverbials. Journal of West African Languages, 23.2: 47-71.

Sauerland, U. \& F. Heck (2003) LF-Intervention Effects in Pied-Piping. Proceedings of Northeast Linguistics Society 33. CITY?

Yang, B. (2005) Intervention effect: aspect, how/why asymmetry, and strongweak contrast. Talk presented at the Third Workshop on Theoretical East AsianLinguistics, Harvard University. 
Zubizarreta, M L. (no date) Intervention effects in the French wh-in-situconstruction: Syntax or Interpretation?. A Romance Perspective in LangugageKnowledge and Use. Selected Papers from the $31^{\text {st }}$ Linguistic Symposium onRomance Languages. Amsterdam/Philadelphia. 